\title{
OS AVANÇOS DA CIÊNCIA DO PRESENTE DA MODERNIDADE INDUSTRIAL E A ENCARNAÇÃO ARISTOCRÁTICA DO PASSADO ANTIGO E MEDIEVAL EM DRÁCULA, DE BRAM STOKER
}

\section{THE ADVANCES IN THE SCIENCE OF THE PRESENT OF INDUSTRIAL MODERNITY AND THE ARISTOCRATIC INCARNATION OF THE ANCIENT AND MEDIEVAL PAST IN DRACULA, BY BRAM STOKER.}

Resumo: O presente artigo buscará, através de uma análise do enredo e um debate historiográfico acerca do romance Drácula (1897), de Bram Stoker, apresentar as contradições presentes na sociedade onde a obra foi publicada e como se expressam no escrito. Mais precisamente, o intuito será o de investigar como o autor se relacionava com o Romantismo e a forma com que sua obra representa o avanço da ciência durante o século XIX. Além disso, em seu contexto de publicação mais próximo, se colocando em oposição e até mesmo embate contra o passado medieval nobiliárquico que se encarna na figura do principal antagonista da trajetória apresentada pelo autor, o Conde Drácula.

Palavras-chave: Drácula; Romantismo; Ciência; Industrial.

Abstract: Through an analysis of the plot and a historiographical debate about Bram Stoker's novel Dracula (1897), the present article aims to depict the contradictions present in the society where the work was published and how they are expressed in writing. More precisely, the objective will be to investigate how the author related to Romanticism and the way in which his work represents the advance of science during the nineteenth century. Moreover, in its closest publishing context, it stands in opposition and even clashes with the medieval nobiliarchic past that is

${ }^{1}$ Graduando em História (Licenciatura e Bacharelado) pela Universidade Federal do Paraná (UFPR). 
embodied in the figure of the main antagonist of the trajectory presented by the author, Count Dracula.

Keywords: Dracula; Romanticism; Science; Industrial.

Bram Stoker nasceu em Clontarf, um subúrbio em Dublin, na Irlanda. Após casar-se em 1878 com Florence Balcombe, mudou-se para Londres, onde passou a trabalhar como assistente do autor Henry Irving, do qual se tornou amigo posteriormente. Stoker escreveu diversos livros, além de desenvolver diversas adaptações de seus escritos para o teatro, dando origem a algumas peças. Após sete anos de pesquisa, publica sua principal e mais conhecida obra, Drácula, em 1897. Formado em Matemática, o autor faleceu em Londres, em 20 de abril de 1912.

O Romance em si configura-se em um compilado de diversos fragmentos de cartas e diários de personagens, além de notícias de jornais. Integrando o gênero do horror clássico (que busca tratar sobre tópicos de nossa sociedade através do inimaginável, trazendo a tona os medos humanos), o romance teve muitas influências externas que contribuíram para que se tornasse um ícone do segmento, juntamente com obras como "Frankenstein" e "O Médico e o Monstro". Entre estas influências se destacam as novelas góticas muito populares na Inglaterra no início do século XIX e os contos de autores como Edgar Allan Poe. Dessa forma, o enredo se desenvolve através da perspectiva de seis personagens: Lucy Westenra, Arthur Holmwood, John Seward, Jonathan Harker, Mina Murray (posteriormente Sra. Harker) e Quincey Morris. No entanto, outros personagens vitais se apresentam ao longo da história, apesar de não deixarem registros escritos extensos (ou nenhum). São eles: Abraham Van 
Helsing (que registra apenas duas pequenas mensagens) e o próprio Drácula.

O enredo se inicia com a visita de Jonathan Harker à Transilvânia, enquanto corretor de imóveis, para efetuar um negócio com o Conde, que deseja se mudar para Londres. Com a vinda de Drácula para a Inglaterra, a vida dos personagens muda drasticamente, dando origem ao desenrolar da trama que se encerra com a perseguição do vampiro até a sua morada na Transilvânia.

Em seu lançamento, a obra não teve grande sucesso, mas recebeu boas avaliações de autores notórios de seu tempo, como Sir Arthur Conan Doyle (renomado autor das histórias do detetive Sherlock Holmes, que possuía grande expressão e renome no meio literário). A popularidade do romance se efetivou através de suas adaptações para o cinema ${ }^{2}$ nas décadas de 20 e de 30 do século XX, fazendo com que fosse revisitado e se tornasse amplamente conhecido. Algumas das principais adaptações que disseminaram a obra foram Nosferatu (1922), uma adaptação não autorizada do romance que teve de criar diversas alterações de roteiro (e de características do próprio personagem principal) para ser lançado e a versão lançada pela Universal, Drácula (1931), que contava com Béla Lugosi como o conde Drácula.

Por mais que o período Vitoriano seja uma referência da prosperidade e expansão do imperialismo da Pax Brittanica, um clima de mórbido tomava o Reino Unido no contexto de publicação do romance,

${ }^{2}$ Outros exemplos destas adaptações que se destacaram são: Drácula (1958), com Christopher Lee, Drácula (1977) pela BBC, e Drácula de Bram Stoker (1992) sendo esta a tentativa hollywoodiana de adaptar a trama. 
muito devido à morte do Príncipe Consorte Francisco Alberto Augusto Carlos Emanuel, marido da Rainha Vitória. A morte do príncipe deixou não apenas a Rainha, mas também toda a nação em um profundo luto, contribuindo para a ambientação das novelas góticas que influenciaram Stoker. Tendo em vista os elementos citados acima, é de vital importância ressaltar o quanto este romance é uma expressão de seu tempo e contexto, trazendo à tona diversos temores, vivências e entusiasmos da Inglaterra Vitoriana. Exemplo disto se dá no caso do tratamento das doenças venéreas, da sexualidade e prostituição neste período. A partir da década de 1820, as forças armadas inglesas atestaram uma grande propagação de doenças venéreas em seus soldados, fenômeno que se repetiu nas décadas de 1850 e 1860 .

Devido a estes e outros eventos, a promiscuidade sexual passou a ser vista como um grande mal social. A “culpa" e responsabilidade destas dinâmicas recaíram, em grande parte, sobre as mulheres, cuja sexualidade deveria então ser controlada e expressamente reprimida, existindo apenas para satisfazer os desejos de seu marido. Nesta perspectiva, a própria medicina se colocava como um agente controlador do corpo feminino e de sua própria sexualidade, classificando determinadas atitudes que apresentavam determinada emancipação enquanto distúrbios psicológicos e doenças físicas. De acordo com Leila S. May (1998), em seu artigo Foul Things of the Night, dentre estas, as mais responsabilizadas neste temor seriam as prostitutas, devido a sua condição enquanto párias sociais, elemento que traz grande influência na representação feminina do romance: 


\begin{abstract}
A maior ansiedade parece ser a da decomposição moral e social, como se o fedor da morte pudesse ser detectado nas próprias galerias da sociedade. Alguns sinais de decomposição moral eram palpáveis nas sombras daquelas galerias. Por exemplo, para a mente vitoriana, a prostituta representava a decadência cujo potencial era a contaminação do corpo social. No entanto, é como se ela não suportasse o peso dos medos vitorianos; estes foram deslocados para além dela e se concentraram em torno da imagem de um monstro menos natural. $\mathrm{O}$ paralelismo entre o vampiro e a prostituta demonstra a intensificação do medo burguês quase ao ponto de uma estranha apoteose. ${ }^{3}$ (MAY, 1998: 16).
\end{abstract}

Este temor e visão acerca da sexualidade feminina muito se expressa na obra de Stoker, na qual o Conde (ao alimentar-se apenas do sangue de belas mulheres) "corrompe-as", tornando-as impuras e aflorando sua sexualidade. Exemplo disso é perceptível no caso de Lucy Westenra, uma mulher "virtuosa" de acordo com os padrões de seu tempo em vida, mas que ao ser vampirizada utilizava-se da sexualidade para atrair e enganar aqueles que queriam destruí-la:

A frieza daquele gesto arrancou um gemido agudo de Arthur; quando ela avançou em sua direção com os braços estendidos

\footnotetext{
3 No original: "The greatest anxiety seems to be that of moral and social decomposition, as if the stench of death might be detected in the very galleries of society. Some signs of moral decomposition were palpable in the shadows of those galleries. For example, to the Victorian mind, the prostitute represented the decay whose potential was the contamination of the social body. Yet, it is as though even she could not bear the weight of Victorian fears; these were displaced beyond her and concentrated around the image of a monster most unnatural. The parallelism between the vampire and the prostitute demonstrates the intensification of bourgeois dread almost to the point of an uncanny apotheosis". [Tradução livre de Vinícius Fávero].
} 
e um sorriso lascivo, ele recuou e escondeu o rosto entre as mãos.

Ela continuou avançando, porém, e disse com uma graça lânguida e voluptuosa:

-Venha, Arthur. Deixe esses outros e venha. Meus braços estão famintos por você. Venha, e poderemos descansar juntos. Venha, meu marido, venha! (STOKER, 2014: 249).

Dessa forma, outro elemento que se evidencia como uma expressão de seu contexto ao longo da obra de Stoker é o entusiasmo com os avanços científicos de seu tempo. Tal dinâmica é trazida à tona, constantemente, através dos recursos e conhecimentos com os quais os personagens se utilizam para lutar contra o vampiro. Este, por sua vez, encarna tudo aquilo que se faz enquanto "ultrapassado" naquele momento, caracterizando-se como a força maléfica que vai na contramão destes avanços e descobertas da humanidade. Assim, segundo Lucia de La Rocque e Luiz Antonio Teixeira:

Através dos tempos, a literatura tem dado voz aos medos e esperanças gerados pelas descobertas científicas e retratado as imagens e mitos em torno da própria ideia de ciência. (...) No século XIX, o avanço tecnológico fez com que muitas visões futuristas, que se acumulavam desde o Renascimento, se tornassem parte do cotidiano das grandes cidades. É, portanto, natural que essa época tenha testemunhado não só o nascimento do gênero literário que ficou mais tarde conhecido como ficção científica, mas também uma produção bastante extensa dessa literatura nascente, que se volta então para os efeitos danosos ou benfazejos do desenvolvimento científico e tecnológico (ROCQUE, TEIXEIRA, 2001: 12). 
Através destas dinâmicas, se faz necessário localizar e estabelecer como Stoker se configurava e relacionava em meio aos movimentos literários de seu contexto. Não apenas isso, mas também situar estes em meio às dinâmicas e processos históricos do século XIX.

Durante as últimas décadas do século XVIII, deu-se origem na Europa ao movimento filosófico, político e artístico conhecido como Romantismo. Este se desenvolveu de forma mais específica e se perpetuou no decorrer do século XIX, expressando-se em perspectivas ideológicas e obras literárias de forma muito diversa, sendo um movimento com várias contradições e rusgas internas. Estendendo-se tais contradições desde concepções que buscavam restituir valores medievais a partir de uma crítica à sociedade burguesa estabelecida através de eventos como a Revolução Francesa, até compreensões revolucionárias para o período do mesmo movimento, que variavam de vertentes populistas até outras vinculadas a correntes como a do socialismo científico.

No entanto, entre todos estes aspectos, existem pontos em comum que delimitam o movimento. De acordo com Michael Löwy e Robert Sayre (2015) em seu escrito, Revolta e Melancolia, o Romantismo na Contracorrente da Modernidade:

Indiquemos de pronto, e em duas palavras, a essência de nossa concepção: para nós, o romantismo representa uma crítica da modernidade, isto é, da civilização capitalista, em nome de valores e ideias do passado (pré-capitalista, pré-moderno). Pode-se dizer que desde a sua origem o romantismo é iluminado pela dupla luz da estrela da revolta e do "sol negro da melancolia" (LÖWY, SAYRE, 2015: 38). 
Assim, é possível percebermos o Romantismo enquanto uma autocrítica da Modernidade, efetuada por diversos pensadores que se desiludiam com o tempo em que viviam. Tal desencantamento se dava por uma série de fatores. Exemplo disso se vê presente através das críticas direcionadas à crescente quantificação e mecanização das relações do período, ocasionando na dissolução dos vínculos sociais.

Através destas críticas, os autores de tal movimento buscavam reencantar o mundo e a natureza, que em sua concepção encontrava-se coisificada. Para isso, se utilizavam de lendas e mitos provenientes de tradições de seu passado. Dessa forma, o que esses autores buscavam eram mudanças frente ao prosseguimento da Modernidade, fossem estas por vias revolucionárias, reformistas, ou pelo reavivamento de antigas tradições.

Tendo em vista tais elementos, é perceptível a dificuldade em classificar Stoker e seu romance como pertencentes ao movimento romântico. A crítica presente no decorrer das páginas do livro não se direciona ao seu presente e sim ao passado, que se personifica na figura do próprio Conde Drácula. Não se sabe ao certo a idade que ele possui, devido a sua vida longeva derivada do vampirismo, mas é dito que este se levanta de seu refúgio maligno todas as noites há mais de cinco séculos. Em toda a obra, o único personagem a mencionar e discorrer sobre o passado é o Conde, fazendo-o ao ressaltar sua nobreza e o poder de sua ascendência e família e trazendo à tona fatos que remontam o período Antigo, percorrendo uma trajetória até a Idade Média. Além disso, também exalta a história de seu país, suas batalhas, guerras, sua formação e o papel vital que o sangue de sua família tomou em todo este processo: 
Nós, szeklers, temos o direito de nos sentirmos orgulhosos, pois em nossas veias corre o sangue de muitas raças valentes que travaram lutas acirradas pelo poder. Aqui, neste redemoinho de raças europeias, a tribo Úgrica trouxe da Islândia o espírito guerreiro que lhe foi dado por Thor e Odin. (...) Aqui, também, quando chegaram encontraram os hunos, cuja fúria guerreira varrera a terra como um incêndio, a ponto de a gente que morria acreditar que nas veias de seus inimigos corria o sangue daquelas antigas feiticeiras que, expulsas da Cítia acasalavam-se com os demônios nos desertos. Tolos, tolos! Que demônio ou feiticeira algum dia foi tão grande quanto Átila, cujo sangue cujo sangue corre nessas veias? Ele ergueu os braços. - Não é de se admirar que fôssemos uma raça de conquistadores; que tivéssemos orgulho; (...) Quando foi redimida aquela grande vergonha de minha nação, a vergonha de Cassova, quando as bandeiras dos valáquios e dos magiares tombaram sobre o Crescente? Quem, se não um homem de minha raça, cruzou o Danúbio em Voivóde e derrotou os turcos em sua própria terra? Era de fato um Drácula! (STOKER, 2014: 39).

Neste personagem de tanta volúpia, o autor coloca toda a crueldade, toda a maldade e toda referência ao passado presente no livro. Ao associar as tradições nobiliárquicas e a valorização do sangue e herança ao seu vilão, Stoker posiciona-se claramente em crítica a estes elementos, associando-os não só a um passado que, em sua visão, encontra-se ultrapassado, mas também a um monstro que esbraveja acerca de seu orgulho e sua família. Esta tradição e passado são o alicerce que sustenta seu poder que, por ironia, é passado através do sangue. No entanto, as associações com intuito crítico à figura do Conde, morto-vivo, não se encerram neste aspecto e podem se tornar muito mais pejorativas. 
Através de sua expansão, a Inglaterra consolidou-se, ao longo da era Vitoriana, como o maior dos impérios europeus. Os territórios em sua posse se estendiam desde a Irlanda, colônias na África (como Uganda e Nigéria), o Extremo Oriente (como Hong Kong e Malásia), partes do Oriente Médio (exemplos disso são os trechos do Iraque e Egito em seu poder), países na América (como o Canadá e Jamaica), praticamente toda a Oceania conhecida naquele tempo (Austrália e Nova Zelândia) e, por fim, seu território mais precioso, a Índia.

Este controle político, cultural, econômico e social, sobre esta vasta gama de populações, fez com que o contato com suas culturas e realidades criassem interesse e gosto pelo "diferente", visto por eles enquanto “exótico". No entanto, tal processo não se consolidou em aceitação e procura pela compreensão pela alteridade, mas sim em um reforço do projeto e imaginário civilizador inglês.

Estes processos impõem grandes reflexos sobre a arte, principalmente na literatura. Neste momento, diversos romances serão publicados contendo como fortes elementos o deslumbramento e superioridade do homem branco com terras distantes e populações exóticas. Ao longo da obra de Stoker, isto se torna evidente. Suas descrições acerca dos costumes dos povos provenientes do leste europeu (os quais Jonathan Harker testemunha em suas viagens) sempre carregam um ar depreciativo, categorizando tais populações enquanto bárbaras e incultas. Mas, ainda há mais elementos a tratar neste quesito. A escolha do autor em colocar a presença do Conde Drácula como um nobre e um monstro proveniente destas culturas vêm recheada de significados, sendo que a própria 
representação da figura do vampiro também se relaciona com esta perspectiva. Segundo Arturo Alejandro Gonzales Y Rodrigues Branco:

\begin{abstract}
Essa perspectiva sugere que na Inglaterra a figura do vampiro se consolidou, particularmente, neste imaginário literário e era representado no real apenas como uma metáfora moralista sobre a superioridade anglo-saxã em relação aos dominados. Nestes romances, o vampiro era mostrado como um estrangeiro de algum dos cantos escuros da Terra, moralmente e sexualmente depravado, sedutor de donzelas, covarde, desonrado e decadente, sem os traços de civilização ou "masculinidade" vitorianos. O herói, normalmente um rapaz vitoriano, "másculo", honrado e casto, antagonizava o vampiro e, com exceção das narrativas mais trágicas, vencia o duelo contra seu inimigo ao final do enredo (BRANCO, 2009: 42).
\end{abstract}

Assim, é perceptível a escolha do autor em apresentar, não apenas um nobre depravado enquanto um monstro, mas também um estrangeiro de uma terra longínqua, associando as demais características de Drácula a esta visão. Ao estender seu domínio sobre estas populações, o Conde as aterroriza praticamente durante todas as noites, atacando moradores e roubando suas crianças. No entanto, ainda assim, diversos setores destas populações o auxiliam em seus propósitos maléficos, sendo que seus principais servos são os ciganos, outra população marginalizada e depreciada.

Porém, em sua vinda para a Inglaterra, Drácula encontra opositores que o enfrentam e acuam, fazendo com que tenha que retornar em fuga para seus domínios. Seus inimigos estão munidos da arma que, através da concepção e apresentação de Stoker, torna-se a mais potente de seu tempo: 
a Ciência. $\mathrm{O}$ autor faz com que a Ciência se apresente como a luz que se opõe às trevas do estrangeiro, do passado e tradição. Ciência esta que está muito vinculada ao processo civilizador inglês e a forma com que este se configurava neste contexto. Não estando apenas vinculada a ele, a Ciência servia aos seus interesses, no sentido de justificar sua dominação (ironicamente, utilizando-se de processos nada científicos), a partir de movimentos como o do Darwinismo Social. Assim, é perceptível o fato de que tais processos de avanço científico eram feitos para um grupo seleto de pessoas, sendo destinados e direcionados para um grupo também seleto e restrito.

Tais elementos se evidenciam a partir da caracterização do principal algoz do Conde, o Prof. Dr. Abraham Van Helsing. O holandês, além de médico, é um filósofo e metafísico. Sua chegada e presença trazem grandes mudanças para a trajetória do enredo, ao passo que Van Helsing encabeça e lidera as investigações e investidas contra Drácula. Stoker apresenta seu conhecimento e saber enquanto sua principal arma, características que se salientam, inclusive, através de sua própria descrição física, narrada por Mina Harker:

Levantei-me e me inclinei, e ele veio até mim; um homem de peso médio, compleição forte, os ombros aprumados, um peito largo e um pescoço firme sobre o tronco, como a cabeça sobre o pescoço. O porte da cabeça impressiona de saída, pois parece indicar pensamento e poder; é uma cabeça nobre, bem-proporcionada, ampla e larga atrás das orelhas (STOKER, 2014: 214). 
Com isso, é válido apontar que a postura de Van Helsing frente à Ciência se difere da dos demais personagens. Através da empiria, o holandês não prova apenas a efetividade de métodos científicos convencionais, mas também de superstições e tradições folclóricas, utilizando-se de truques como o de uso de alho contra o vampiro, assim opondo-se ao ceticismo na luta contra o mal, unindo ambas as frentes em seu combate.

Tendo em vista tais dinâmicas, Helsing analisa a Ciência enquanto uma ferramenta da humanidade para avançar e, através de seu ofício como médico, trazer cura para os enfermos da trama. Assim, o progresso é visto de maneira muito entusiasta na obra, onde avanços tecnológicos de época são apresentados a todo o momento enquanto inovadores (como a transfusão sanguínea, o fonógrafo e a taquigrafia). Neste sentido, é interessante apontar que outras obras do gênero provenientes do mesmo contexto se apresentavam mais pessimistas em relação a tal progresso tecnológico. Exemplo disso são as perspectivas apresentadas em Frankenstein (onde, através da ciência, a vida é criada de forma não-natural, dando origem a um monstro) e O Médico e o Monstro (onde o uso da ciência faz com que o médico crie um monstro dentro de si). Dessa forma, é perceptível que o debate acerca dos avanços tecnológicos do período se apresentava de maneira muito diversa. Avanços estes que são constantemente empregados na luta contra o Conde. Dessa forma, de acordo com Lucia de La Rocque e Luiz Antonio Teixeira (2001: 22):

Em Drácula, a ciência, seus métodos, saberes e instrumentos são usados como armas contra o vilão que nomeia o romance, 
e assim a obra, apesar de estar mais bem situada no gênero de horror que de ficção científica, realiza algo que talvez seja muito mais eficiente na divulgação, entre o público leitor, de uma noção positiva de ciência: personifica a idéia do cientista como detentor da chave de um conhecimento que não é perigoso, mas, ao contrário, útil à humanidade.

A oposição entre o passado, o estrangeiro e o nobiliárquico em relação ao progresso e a ciência se faz clara ao longo de toda a trajetória e embate entre o grupo e o Conde. Este conflito se inicia a partir do processo de vampirização de Lucy Westenra, onde o personagem de Van Helsing é introduzido. Toda a dinâmica de tratamento em relação à mulher que estava sendo alvejada por Drácula se dá através da utilização do progresso tecnológico de seu tempo e elementos do folclore popular (como o uso dos dentes de alho, símbolos sagrados e lendas para enfrentar o vampiro).

O progresso do tratamento e recuperação de Lucy só encontra empecilhos pela interferência de sua mãe, que, ao desfazer medidas utilizadas por Van Helsing e John Seward, possibilita que o vampiro possa retornar a sugar o sangue de sua filha. No entanto, Stoker segue à risca a restrição de gênero empregada ao conhecimento em seu tempo. Este se faz reservado ao domínio masculino, onde dentre todos os personagens cientistas e profissionais da saúde, nenhum é do sexo feminino. Como explicita Michelle Perrot, o conhecimento feminino, quando apontado pelo patriarcado, era considerado enquanto desvalorizado:

Passa-se, assim, da bordadeira à costureira da fábrica, da pianista à datilógrafa, e depois, à mecanógrafa, da costureira tímida à montadora de transistores, como consequência lógica, sem que fosse preciso aprendizagem ou reciclagem, mas 
simplesmente daquela "destreza" que se atribui geralmente às mulheres, ao passo que lhes é recusada qualquer outra "qualificação". Elogiam "dedos de fada"; negam-lhe a ciência que por si só funda um ensino. Empírico, ou mágico, o seu saber é sem qualidades (PERROT, 2005: 226).

Por fim, é importante ressaltar que o elemento religioso também se manifesta como fundamental para o desenrolar da história. $\mathrm{O}$ simbolismo cristão (seja por meio da hóstia sagrada ou do crucifixo) é amplamente utilizado na luta contra o vampiro. A luta entre o Bem e o Mal, da luz contra as trevas, é um elemento importante tanto na narrativa, quanto na fé cristã, a qual também se manifesta enquanto influenciadora para o andar da história.

O conhecimento religioso se apresenta a partir da figura do próprio Van Helsing, o qual arma seus companheiros com "kits sobrenaturais". A presença de tais símbolos cristãos, identicamente, cria conflitos internos dentre o grupo de investigadores, principalmente porque muitos se configuram enquanto céticos frente a estas medidas e estratégias propostas pelo doutor.

Assim, tendo em vista os elementos já apresentados, percebe-se a forma com que o autor e a obra literária em si são um produto de seu contexto. Através de todas as dinâmicas científicas da Modernidade Industrial, dos contatos culturais gerados pela expansão imperialista inglesa e do processo de consolidação da moral burguesa na sociedade vitoriana, o autor apresenta sua crítica ao passado, à exaltação do presente e reafirmação do projeto civilizatório inglês. Além disso, a obra também evidencia os temores acerca da sexualidade feminina, da "nova mulher" 
(senhora de sua própria sexualidade e não submissa ao masculino nesse sentido), devido a sua característica de controle sobre seu próprio corpo, através da caracterização dos vampiros e suas armas contra a humanidade.

Por fim, o romance de Stoker se consolida como mais um ícone do gênero literário do horror clássico que evidencia o quanto sua trama vem carregada de significados sociais e culturais. Tais processos perpassam os temores e medos de sua época, mas também os suplantam e apresentam o retrato da perspectiva ideológica de um estrato da população vitoriana, não apenas acerca do conhecimento científico, do folclore popular e do oculto, mas também do mundo à sua volta, suas demais populações e sua própria função frente a estas.

\section{Bibliografia}

BRANCO, Arturo Alejandro Gonzales Y Rodrigues. The Wolf and the Bat The Popular Culture and the English Imaginary of XIX Century. 2009. 172 f. Dissertação (Mestrado em Ciências Humanas) - Universidade Federal de Goiás, Goiânia, 2009.

DRÁCULA. Direção: Tod Browning, Produção: Carl Laemmle Jr, Nova Iorque (EUA): Universal Pictures, 75 min. 1931, P\&B.

DRÁCULA. Direção: Terence Fisher. Produção: Anthony Hinds, Water Oakley (GBR): Hammer Film Productions, 81 min. 1958. P\&B.

DRÁCULA. Direção: Philip Savill. Produção: Barry Morris, Londres (RU): BBC, 155 min., 1977. P\&B.

DRÁCULA de Bram Stoker. Direção: Francis Ford Coppola. Produção: Francis Ford Coppola e Fred Fuchs, Culver City (EUA): Columbia Pictures, 128 min. 1992. P\&B. 
HOBSBAWM, Eric J. A Era dos Impérios. Rio de Janeiro: Paz e Terra, 1988.

LÖWY, M. e SAYRE, R. O que é romantismo? Uma tentativa de redefinição. In: Revolta e melancolia. São Paulo: Boitempo, 2015

MAY, Leila S.Foul Things of the Night: Dread in the Victorian Body. Modern Humanities Research Association. 1998. Disponível em: $<$ https://www.jstor.org/stable/3733619?origin=JSTOR-pdf\&seq=1\#page_sc an_tab_contents $>$. Acesso em: 01 jun. 2019.

NOSFERATU. Direção: Friedrich Wilhelm Murnau. Produtor: Enrico Dieckmann e Albin Grau, Berlim (ALE): Krefeld: Prana-film, 94 min. 1922. P\&B.

PERROT, Michelle. As mulheres ou os silêncios da história. Bauru: Editora da Universidade do Sagrado Coração, 2005.

ROCQUE, L. de L. e TEIXEIRA, L. A.: Frankenstein, de Mary Shelley e Drácula, de Bram Stoker: gênero e ciência na literatura. História, Ciências, Saúde — Manguinhos, vol. VIII(1), p. 10-34, mar.-jun. 2001.

RODRIGUES, A. C. F. Drácula de Bram Stoker: Gênero Sexualidade e Saúde Pública na Inglaterra Vitoriana. In: XIX Encontro Regional de História: Poder, Violência e Exclusão, 2008, ANPUH-SP. Anais do XIX encontro Regional de História: Poder, Violência e Exclusão. São Paulo, 2008.

STOKER, Bram. Drácula. 2. ed. Rio de Janeiro: Nova Fronteira, 2014.

Recebido: $19 / 08 / 2019$

Aceito: 19/05/2020 